\title{
Efficiency of social innovation and investment projects for the sustainable economic development
}

\author{
Valerya Glazkova ${ }^{1, *}$ \\ ${ }^{1}$ Moscow State University of Civil Engineering, 129337, 26, Yaroslavskoye Shosse, Moscow, Russia
}

\begin{abstract}
The need of ecological and demographic equilibrium demands implementation of social investments, including business within realization of corporate social responsibility that, in turn, needs validity of calculations for the assessment of efficiency and effectiveness of the respective projects. Nowadays, many companies develop their own techniques of the social projects' assessment, which can use the same parameter, but measure it in another way. And in this sense, they often become incomparable. The main contents of the concept of the corporate social responsibility are stated, and the existing indicators and approaches to the assessment of corporate social responsibility of business are considered in the article. The dynamics of the development of corporate social responsibility in Russia is also presented in the article. The methodical approach to the efficiency of the investments carried out by business and aimed at the development of workers, local community and ecology is the result of the research. These results can be used for the assessment of the efficiency of the projects implemented by business within corporate social responsibility.
\end{abstract}

\section{Introduction}

The interaction of business and government, reflecting the interests of society, is the most important factor of the sustainable development of the country. Social responsibility of business belongs to the necessary elements of social policy, promoting relative equilibration of the social benefits in the society. Nowadays, modern development of the world entered such a stage, when the limitation of natural resources, unreliability of ecological and demographic equilibrium become more notable.

According to the theory of "the prisoner's dilemma", the coordinated cooperative behavior of the society gives a great benefit than the individual behavior, carried out only in one's private interests. Valuable reference points of people, including solidary behavior, both all people in world scales, and business and the power in scales of economies, play an important role in the solution of these questions.

Effective interaction between business and power, eventually, leads to the stable development of society and to the growth in the prosperity of the population [1].

\footnotetext{
*Corresponding author: leram86@mail.ru angela-1309.m@yandex.ru
} 
The main load of the development of the social sphere, certainly, lays down on the state, but business also participates in the process of formation and development of civil society [2]. It is carried out by the means of implementation of the concept of the corporate social responsibility (CSR), which is defined by the world council of business as the obligation of business to make contribution to the sustainable economic development, labour relations with workers, their families, local community and society in general for the improvement of their life quality.

The objective need of the participation of business in the development of social projects developed for several reasons:

- existence of monotowns, where all the infrastructure and population are tied to the enterprise;

- high social expectations at low social activity of the population: inhabitants of the regions expect the solution of all the social problems from the company, local and federal authorities, but on the whole, they are not ready to make independent efforts for the solution of social problems;

- high level of poverty in the regions and low level of financing of the social sphere at the expense of budgetary sources.

At the same time, it is necessary to remember that the concept of social responsibility in case of its skillful realization, is capable to bring not only additional expenses for the companies, but also to improve its qualitative characteristics if to consider this matter in terms of moral economy (Table 1).

Table 1. Advantages from CSR to the stakeholder groups

\begin{tabular}{|c|c|}
\hline Stakeholder & Positive influence from the introduction of CSR \\
\hline \multirow{4}{*}{$\begin{array}{l}\text { Shareholders } \\
\text { and } \\
\text { management of } \\
\text { the company }\end{array}$} & $\begin{array}{l}\text { The reputation of the organization, recognition of its brand are } \\
\text { getting better; that influences the increase in volumes of sales and } \\
\text { growth rates of the company. }\end{array}$ \\
\hline & $\begin{array}{l}\text { Existence of social programmes at the enterprise can positively } \\
\text { influence the investors decisions on the investments into the } \\
\text { company }\end{array}$ \\
\hline & $\begin{array}{l}\text { Decrease in operating expenses, for example, due to reduction of } \\
\text { dfects and industrial wastes, increase in energy efficiency, sale or } \\
\text { processing of materials, etc. }\end{array}$ \\
\hline & $\begin{array}{l}\text { Claims from regulating boards to the companies, implementing } \\
\text { social projects, are reduced, so, the process of management of risks } \\
\text { at the enterprise improves. }\end{array}$ \\
\hline $\begin{array}{l}\text { Staff of the } \\
\text { company }\end{array}$ & $\begin{array}{l}\text { Favorable climate at the enterprise as well as favorable social } \\
\text { environment due to providing employees of the company with } \\
\text { social guarantees are created. }\end{array}$ \\
\hline $\begin{array}{l}\text { Population and } \\
\text { society }\end{array}$ & Growth of quality of life in the region. \\
\hline $\begin{array}{l}\text { Future } \\
\text { generations }\end{array}$ & $\begin{array}{l}\text { Promotes the implementation of the concept of sustainable } \\
\text { development, decrease in the level of pollution, preservation of } \\
\text { resources, natural and cultural heritage. }\end{array}$ \\
\hline
\end{tabular}

No doubts, social activity of the enterprise and its reputation are interconnected. As the corporate social responsibility is focused on the sustainable development, it is possible to consider it, as a factor of a long-term competitive benefit of the organization. Socially responsible company, as a rule, publishes the corresponding reports, so, it is possible to speak about openness of the firm. Social investments according to their economic nature suppose charity; that proves the growth of image of the firm and growth of competitive 
advantages. It is proved by many economists, such as: Blagov Yu.E., Smooth I.V., Batayev B.S., E. Pertsev, Suyev Yu.V., E. Kiryushin and others [3].

If the firm makes investments into social programmes, thereby providing social guarantees to the workers and guaranteeing quality and safety of the sold products and services, then the enterprise expects favorable social environment in the long term and therefor steady financial and economic position.

Understanding of the advantage of social responsibility for business leads to the fact that since 2006, the quantity of the Russian companies publishing reports on their social responsibility tends to increase (Figure 1): by 2015, there will be twice more companies, realizing the principles of CSR in comparison with 2013. However, we will note that since 2013 , this indicator goes for small recession - by 2015, the number of the companies publishing non-financial reports decreases by $16 \%$.

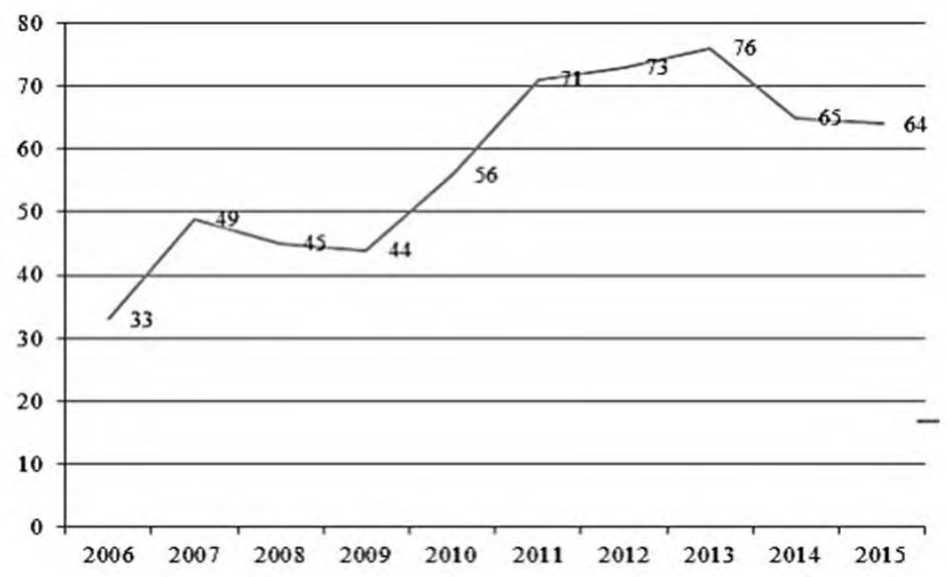

Fig. 1. Dynamics of development of CSR in Russia (Quantity of companies, publishing their financial reports)

Despite such dynamics in the Russian practice, it is obvious that in the modern world CSR has already wide recognition and act as an important component of the modern successful company. Of course, it is difficult to calculate the payback period for social investments, and it can sometimes be absent, but that does not mean that they do not have any positive effect.

\section{Methods}

Scientific concepts of the leading Russian and foreign scientists, concerning the assessment of the innovative-and-investment projects, social innovations, investments efficiency, as well as concerning the principles of the assessment of some quality indicators act as the methodological base of this research. Some fundamental works and publications on the studied matter in scientific periodicals; materials of the international and All-Russian conferences and seminars were studied. Such general scientific methods of research as: induction, deduction, analysis, synthesis; system approach; economic-mathematical and statistical methods; method of comparative analysis, analogies, observation, poll, method of expert evaluations were used.

Now many companies develop their own techniques which can use the same parameter, but can measure it differently. And thus, they often become incomparable. In Russia there are no distinct and clear criteria for the evaluation of corporate social responsibility, no idea about ethical principles of modern business and economic benefits of socially responsible 
behavior. The development of the Standard "Social reporting of the enterprises and organizations registered in the Russian Federation" by Chamber of Commerce and Industry of Russia became an important step in this direction.

The introduction of the international standard of the Global initiative of the reporting in the field of sustainable development (GRI) by the principle of "three baskets" or "a triune result" became the first stage according to the reporting of CSR and sustainable development: economy of the companies, ecology of production and social policy. This form of the reporting represents an initiative of the company to show to a wide range of interested parties its cost, environmental and social efficiency. Parameters of sustainable development of the enterprise in the GRI system are presented in Table 2.

In the context of the reporting of GRI indicators can be both quantitative and qualitative. Though the use of quantitative or qualitative sizes is connected with many advantages, they can be unreliable, incomplete, or ambiguous within the effectiveness assessment in certain areas. GRI considers the quality indicators demanding the text description as the supplementing organizations, quantitative, and necessary for formation of a full picture of economic, ecological and social effectiveness [4].

Table 2. Parameters of sustainable development in the GRI system

\begin{tabular}{|c|c|c|}
\hline \multirow{2}{*}{\multicolumn{2}{|c|}{$\begin{array}{l}\text { Type of parameters } \\
\text { (depending on efficiency) } \\
\text { Economical } \\
\end{array}$}} & Parameters \\
\hline & & Direct economic influence \\
\hline \multicolumn{2}{|c|}{ Ecological } & $\begin{array}{l}\text { Materials, energy, water, biodiversity, emissions, drains } \\
\text { and waste, suppliers, products and services, respect for } \\
\text { norms and standards, transport }\end{array}$ \\
\hline \multirow{4}{*}{ Social } & $\begin{array}{l}\text { Use of labour and } \\
\text { providing worthy } \\
\text { working } \\
\text { conditions }\end{array}$ & $\begin{array}{l}\text { Practice of employment, relation between the management } \\
\text { and personnel, health protection and safety of work, } \\
\text { training and vocational training, variety and equal } \\
\text { opportunities }\end{array}$ \\
\hline & Human rights & $\begin{array}{l}\text { Strategy and management, lack of discrimination, freedom } \\
\text { of associations and collective agreement, child labour, } \\
\text { involuntary and obligatory servitude, disciplinary practice, } \\
\text { practice of safety, right of indigenous peoples }\end{array}$ \\
\hline & Society & $\begin{array}{l}\text { Local community, bribery and corruption, financing of } \\
\text { politicians, competition and price policy }\end{array}$ \\
\hline & Products & $\begin{array}{l}\text { Health and safety of consumers, products and services, } \\
\text { advertizing, respect of a private ownership }\end{array}$ \\
\hline
\end{tabular}

In the Russian practice, several methods for calculation of assessment of social responsibility of business were also created. One of them is the calculation of the index of social investments, developed by Association of Managers of Russia.

The qualitative index of social investments is the cornerstone of this technique. The index considers the fact of existence (or absence) any positive parameters at the company respondent. We can distinguish private and general qualitative indexes of social investments. The private index pays off for i-th company, and the general index shows the extent of presence of this qualitative sign for the statistical selection of the companies' respondents. The variable is the cornerstone of the calculation of these indexes, it is 1 if the sign is present at the company, and it is 0 if the sign is absent.

The selection of signs has to be made so that each of them is important for each company. The technique uses three groups of criteria of quality standard of social investments. These three groups are based on 12 indicators, which are most adequately 
characterizing the present stage of development of the Russian companies. The 1st group is the institutional registration of social policy. The 2 nd group is the system of accounting of social actions. This group assumes accounting on four positions, including assessment of efficiency of the carried-out social investments. The 3rd group is the complexity of the carried-out social investments. This group assumes accounting in five directions, including development of local community.

The technique of Association of Managers of Russia considers information on the existence or lack of each of 12 signs and generalizes it in a uniform indicator (the qualitative index of social investments).

There are also techniques of the assessment of voluntary corporate responsibility of the organizations in the Saratov region [5] and the Republic of Bashkortostan. They are identical. The assessment of CSR is carried out in 2 directions: costs of the solution of social problems of workers and members of their families in the organizations and costs of social problems out of the organization, including implementation of social programmes within agreements with the authorities of the region and out of these agreements. Expenses are estimated in value terms, and there is a share of each type of an expense to the total amount of realization of the company further. Further each indicator is estimated according to the 10-mark (10-ball) scale. The sum of balls is the summary indicator of voluntary CSR.

The approach to the CSR assessment, developed by V. Kashin, A. Neshchadin and G. Tulchinsky is interesting. These authors point out three main options of the assessment of the efficiency of social investments:

1. option - in terms of dynamics of growth of social investments and development of social partnership;

2. option - comparison to average values of costs of internal and external social investments and social partnership;

3. option - development of optimum (target) standard indicators of internal and external social investments and the assessment of efficiency as comparison to these indicators.

The fullest and complex is the third option as it assumes identification of priority problems of social development (including concrete region, enterprise). However, depending on the concrete situation and tasks the application and two other options is quite justified [6].

V. Kashin, A. Neshchadin and G. Tulchinsky also suggest to implement the integrated indicator "social expenses per one worker", including salary, social payments, cost of a benefits package, etc. It makes it possible to compare social working conditions both in regional and in branch scale.

The same authors pointed out 4 primary groups of the indicators, characterizing social investments depending on the direction of the corresponding expenses (internal, external) and the fact in what interests and also from whose position (business or society) the efficiency is estimated:

- the internal social investments estimated from the social position (social investments into the human capital, including costs of growth of competence of workers, protection of their work and health, development of corporate culture);

- the internal investments estimated from the positions of the business (social investments into development of the relations with consumers, partners, investors, creditors, competitors);

- the external social investments estimated from the positions of external social environment (social investments into ecology, improvement, housing and public utilities and also social and humanitarian development - health care, culture and art, education and others);

- the external social investments estimated in terms of business (stability of total economic indicators, growth of popularity, recognition and respect). 
The development of this technique is the essential step in the development of assessment of corporate social responsibility as it allows to estimate not only domestic social policy of the organization (as the majority of techniques in the field of CSR assessment), but also the external efficiency of social investments, and their importance for development of society [7].

Thus, business within corporate social responsibility, carries out the social investments aimed at the development of workers, local community, ecology, implementing social projects.

\section{Results}

The technique of the efficiency of social projects assessment, which is considered in the work [8] can be applicable taking into account Russian specifics for assessment of the efficiency of the projects implemented by business within CSR. The technique is developed according to the international standard of the Global initiative of the reporting in the field of sustainable development (GRI) and the principles of sustainable development of the economy; it includes some the indicators that allow considering the interests of future generations, and it can be applied both for the assessment of independent project and to comparison of alternative projects, to the further choice of the most effective one.

The initial option of the technique allows calculating the significance value of the project, its effectiveness, the budgetary and social effect of the project implementation, defining population which quality of life improves as a result of the project implementation and also the quantity of newly created jobs and coefficient of accounting of interests of future generations [9]. Adapting the author's technique for the assessment of efficiency of the social projects implemented by business, we receive the following algorithm of calculation: 1. Assessment of the efficiency of investments in the social projects including implemented due to business according to this technique begins with the justification of expediency and the need of its realization in terms of priorities of socio-economic development of the region and also the provision of the population with the social services.

2. Calculation of the coefficient of the project effectiveness. In the initial author's technique, 7 indicators and 7 corresponding coefficients of the importance for each indicator are presented for the calculation of effectiveness of the project. Calculation of the coefficient of effectiveness for the assessment of efficiency of the social project, implemented due to business is based on the indicators of influence of implementation of the social project on business which can accept the values presented in Table 3 . The coefficient on the corresponding group of indicators, according to the technique makes up 0.1 (it is received in the expert way).

Table 3. Values of indicators of the social project effectiveness for business

\begin{tabular}{|l|l|c|}
\hline \multicolumn{1}{|c|}{ Indicator } & \multicolumn{1}{|c|}{ Desrciption of the indicator } & \multicolumn{1}{|c|}{$\begin{array}{c}\text { Value of the } \\
\text { indicator }\end{array}$} \\
\hline 1 & \multicolumn{1}{|c|}{2} & 3 \\
\hline I7 & Indicators of the influence of the social project implementation on business \\
\hline \multirow{7}{*}{} & $\begin{array}{l}\text { Implementation of the project will lead to the increase in the level of } \\
\text { quality of life and welfare of the staff of the organization implementing } \\
\text { the social project }\end{array}$ & \multirow{2}{*}{0.7} \\
\cline { 2 - 3 } & $\begin{array}{l}\text { Implementation of the project will lead to the improvement of quality of } \\
\text { the social sphere of the enterprise implementing the social project }\end{array}$ & \multirow{2}{*}{0.3} \\
\cline { 2 - 3 } & $\begin{array}{l}\text { Implementation of the project will lead to the improvement of image of } \\
\text { the company and increase in its profit }\end{array}$ & 0 \\
\cline { 2 - 3 } & $\begin{array}{l}\text { Implementation of the social project will not lead to any positive } \\
\text { consequences for the organization }\end{array}$ & \multirow{2}{*}{} \\
\hline
\end{tabular}


3. Calculation of the net present value (NPV). When calculating NPV from the project, it should be noted that, as a rule, the implementation of social projects differs in the minimum economic effect or its absence owing to specifics of social projects [10].

4. Definition of indicators "population which quality of life improves as a result of implementation of the project" and "creation of additional jobs" by the means of direct account [11].

5. Calculation of social effect of the project implementation. The social effect of the project implementation is estimated in case of gain of indicators in 6 social directions: education, health care, culture, physical culture and sport, transport, housing-and-public utilities.

6. Calculation of the coefficient of accounting of interests of the future generations. The coefficient of accounting of interests of the future generations and compliance of the project to the principles of sustainable development of the economy is defined, if the results of the project implementation affected changes in the environment, biodiversity and/or communities positively (the corresponding indicators are summarized) [12].

The social project implemented at the expense of means of business within the concept of corporate social responsibility is considered to be accepted to realization in case of achievement of the following indicators:

- the coefficient of effectiveness of the project makes 0.03 and more;

- the social effect of implementation of the project is 0.2 and more.

In case if at least one of the presented criteria indicators (coefficient of effectiveness and social effect) does not reach the established value, it is not expedient to take cognizance of the project as its realization will not bring any positive social effects.

In case of comparison of alternative projects, it is recommended to apply the rating assessment of the projects, based on the method of distances [13].

Thus, business within corporate social responsibility, carries out the social investments aimed at the development of workers, local community, ecology, implementing social investment projects. The offered author's technique of the assessment of the social projects efficiency which is considered in the work [14] can be applicable, taking into account Russian specifics and for the assessment of the efficiency of the projects implemented by business within CSR. The technique is developed according to the international GRI standard and the principles of sustainable development of the economy.

\section{Conclusion}

Analysing the variety of techniques of the CSR assessment we should note that such assessment has to consider social investments not only from the position of development of the internal business environment, but also in terms of the society welfare development.

The effectiveness of the social project is offered to be estimated in the following directions:

1) for business: improvement of quality of the social sphere of the enterprise, growth of level of quality of life and welfare of the staff of the organization, improvement of image of the company and increase in its profit;

2) for the population and society: creation of additional jobs, growth of quality of life in the region;

3) for future generations: positive changes in the environment, eradications of discrimination, illiteracy and poverty, increase in safety of cultural monuments, etc.

The GRI Standard is of the greatest interest among the CSR assessment techniques considered in the article, since it considers social investments both from the positions of the organizations and from the positions of the population and communities, which can be used during assessment of the social projects' efficiency, taking into account the interests of all the shareholders: states, business, society and future generations. 


\section{References}

1. E. R. Yescombe, E. Farquharson, Public-Private Partnerships for Infrastructure, DOI: 10.1016/B978-0-08-100766-2.00002-4 (2018)

2. M. Röber, Public Private Partnerships (PPP) in Book Handbuch Staat, DOI: 10.1007/978-3-658-20744-1_101

3. E. R. Yescombe, Edward Farquharson, Public-Private Partnerships for Infrastructure (2018) DOI: 10.1016/B978-0-08-100766-2.00028-0

4. A. N. Maloletko, O. V. Kaurova, S. G. Erokhin, Liliia Matraeva, Man in India, 97(21), 15-28 (2017)

5. A. Tamošiūnas, Contemporary Issues in Business, Management and Education (2017) DOI: 10.3846/cbme.2017.057

6. I. Mohd-Sabrun, R. Muhamad, Routledge Research in Sustainability and Business (Routledge, 2019) DOI: 10.4324/9780429057182-3

7. F. Ban, K. Jain, C. H. Papadimitriou, Information Processing Letters, 145 (2019) DOI: 10.1016/j.ipl.2018.12.009

8. E. M. Marchenko, V. V. Glazkova, Assessment of efficiency of social innovative and investment projects. Monograph (Vladimir: Transit ICKX, 2015)

9. V. V. Glazkova, MATEC Web of Conferences, 106 (2017), 08096

10. M. A. Bahauovna, M. A. Bahauovna, International Journal of Applied Engineering Research, 10(23), 43446-434499 (2015)

11. E. M. Akhmetshin, , Kovalenko, et al., Journal of Entrepreneurship Education, 21(2) (2018)

12. A. Mottaeva, MATEC Web of Conferences, 193, 01022 (2018)

13. V. V. Zozulya, L. I. Goncharenko, A. V. Zuikov, G. N. Semenova, Journal of Advanced Research in Law and Economics, 8(5), 1629-1633 (2017)

14. V. V. Glazkova, E. M. Marchenko, MATEC Web of Conferences, 170, 01049 (2018). 